\title{
Inexpensive Video Drop-camera for Surveying Sensitive Benthic Habitats: Applications from Glass Sponge (Hexactinellida) Reefs in Howe Sound, British Columbia
}

\author{
Lena Clayton ${ }^{1,3}$ and Glen DenNison ${ }^{2}$ \\ ${ }^{1}$ Marine Life Sanctuary Society of British Columbia, P.O. Box 54193, Lonsdale West, North Vancouver, British Columbia \\ V7M 3L5 Canada \\ ${ }^{2}$ Triumf, 4004 Wesbrook Mall, Vancouver, British Columbia V6T 2A3 Canada \\ ${ }^{3}$ Corresponding author: lenaclayton@mlssbc.com
}

Clayton, Lena, and Glen Dennison. 2017. Inexpensive video drop-camera for surveying sensitive benthic habitats: applications from glass sponge (Hexactinellida) reefs in Howe Sound, British Columbia. Canadian Field-Naturalist 131(1): 4654. https://doi.org/10.22621/cfn.v131i1.1783

Where marine waters are shallow and bathymetric features are steep, the typically employed multi-beam side scan sonar is not always reliable for identifying complex biological structures. Here, we present a cost-efficient method used in Howe Sound, British Columbia, for bathymetric mapping, exploration, and ground-truthing of glass sponge bioherms. A simple depth sounder and software package was used to produce bathymetric maps. From these maps, prospective sites were selected and surveyed to investigate bioherm presence with a simple drop-camera towed off the bow of a small drifting vessel during calm seas. This method was used during a 4-year citizen science initiative that led to the discovery of 12 glass sponge bioherms in Howe Sound, the first step in protecting these globally unique reefs from the impact of bottom-contact fishing, anchoring, and potential industrial contamination. Before our work using this method, only two glass sponge bioherms had been identified in Howe Sound. The method also proved effective as a means to quantify damage to bioherms from fishing gear.

Key Words: Bioherms; citizen science; drop-camera; glass sponge; sensitive benthic habitats; Howe Sound

\section{Introduction}

Glass sponges are sessile organisms that can form geologically stable habitats, or bioherms, through the accumulation of ancestral skeletal matter and sediment (Cumings and Shrock 1928; Conway et al. 2001; Krautter et al. 2001). These unique habitats, with live sponges growing on top, first appeared during the Devonian period and were abundant throughout the Late Jurassic (Ghiold 1991). Bioherms were thought to have no current living analog until their discovery in Queen Charlotte Sound and Hecate Strait in 1987 (Conway et al. 1991). Bioherms are known to provide important habitat for fish and invertebrates (Marliave et al. 2009; Hogg et al. 2010), along with mass water filtration (Yahel et al. 2007). However, they are at risk of damage from anthropogenic activities, such as fishing, and from pollution and are particularly sensitive benthic habitats (Wassenberg et al. 2002; Cook et al. 2008). Our ability to protect these habitats from damage relies, initially, on our knowledge of their locations.

Since the first discovery of glass sponge bioherms on the western continental shelf of Canada, further exploration has taken place to locate and map bioherms in the Strait of Georgia and Howe Sound (Conway et al. 2001, 2005; Krautter et al. 2001; Chu and Leys 2010). A combination of multi-beam sonar and remotely operated vehicle (ROV) or submersible transects have been used to investigate deep water coral and sponge garden habitat (Conway et al. 1991, 2001, 2005; Krautter et al. 2001; Leys et al. 2004; Chu and Leys 2010; Neves et al. 2014). As well, SCUBA has been employed to supplement ROV ground-truthing in multi-beam surveys of non-glass sponge bioherm benthos (Kendall et al. 2005; Micallef et al. 2012). In Howe Sound, two bioherm sites have been located using multi-beam side scan sonar equipment and ground-truthed by ROV by Fisheries and Oceans Canada (A. Dunham, personal communication, 11 March 2014). To protect this ecologically important and sensitive habitat, bottomcontact fishing, such as commercial and recreational prawn and crab trap fisheries, has been prohibited in these areas as of 12 June 2015 (Fisheries and Oceans Canada 2016).

Multi-beam sonar capitalizes on the distinctive lowintensity backscatter pattern of clay-rich sediments found in reefs compared with the higher-intensity backscatter of reflective glacial sediment that the reefs colonize (Conway et al. 2005). Although this method is effective for surveying large deep areas of the ocean efficiently and characterizing the abiotic benthos (Kendall et al. 2005), it does not allow differentiation of living and dead glass sponge reefs, nor does it have the resolution to function accurately and consistently in shallower areas with steep slopes or pinnacles (Copeland et al. 2013; Ybarra 2015).

To compensate for these limitations, ROVs are often used synchronously with bathymetric maps and/or sonar maps to run video transects over the seafloor for confirmation. ROVs or submersibles can provide realtime video footage of glass sponge bioherms that can confirm the true state of the reef (Leys et al. 2004;

A contribution towards the cost of this publication has been provided by the Thomas Manning Memorial Fund of the Ottawa Field-Naturalists' Club. 
Conway et al. 2005). However, although they are accurate for ground-truthing, ROVs and submersibles are often cost-prohibitive for even well-funded institutions and out of reach for citizen science initiatives. Furthermore, there is the risk of damage to glass sponges by direct contact with an ROV or indirect contact (as wash of the propulsion system may increase sediment load and arrest filter feeding) in such sheltered areas as fjords, where maneuverability is limited (Allwood 1986; Leys and Tompkins 2004; Tompkins-MacDonald and Leys 2008)

Although less common, SCUBA is another method of observation that can be used in the shallower glass sponge bioherms of Howe Sound. This provides a unique opportunity to observe a normally deep water habitat and the organisms themselves first-hand (Marliave et al. 2009). Over the years, SCUBA has proven to be a successful technique for accurately surveying other benthic habitat types and invertebrate populations at a high resolution (Everson and White 1969; Beckley and Branch 1992; Kendall et al. 2005; McGarvey et al. 2010). The primary limitations of SCUBA observation are the restricted time one can safely collect bioherm data at depth and how deep one may undertake observation. Furthermore, as noted with coral reefs, there is a risk of physical habitat damage and disease spread with increased human contact through SCUBA diving (Lamb et al. 2014).

Given the complex bathymetry and shallow waters in areas of Howe Sound, alternative methods for identifying and ground-truthing bioherm locations seem advisable. Drop-cameras have proven successful in supplementing single- and multi-beam echosounders, side scan sonar, and SCUBA observational data in previous shallow water studies (Strong and Lawton 2004; Vandermeulen 2007). As well, drop-cameras have been successfully employed for fish surveys at depth, although there may be some error in findings because of the effect of light at depth on mobile organisms (Morrison and Carbines 2006; Rooper et al. 2015). Here we describe an inexpensive method undertaken through a citizen science initiative to discover and survey glass sponge bioherms in the fjord of Howe Sound, British Columbia.

\section{Methods}

\section{Drop-camera Development}

A small drop-camera system was custom designed to collect underwater observations of bottom substrate from small vessels at a relatively low cost (Table 1, Figure 1). The pressure housing was first modelled and stress simulated using 3D CAD and simulation software (SolidWorks version $2014 \times 64$ edition SP5.0, Dassault Systèmes SolidWorks Corp., Waltham, Massachusetts, USA) before undergoing a series of in-situ pressure tests in Howe Sound and strengthening to resist a final depth of $240 \mathrm{~m}$ (Figure 2A).

To achieve single wire operation, the output video was bottom-side modulated to $61.25 \mathrm{MHz}$ (analog channel 3) and a direct current (DC) was injected topside on the radio frequency signal before routing to the transmission line. At the bottom side, the DC power was separated off, filtered, and passed on to two switching regulators that run in constant current mode to drive two light-emitting diodes (LEDs) mounted in pods that are part of the main pressure housing (Figure 1). The LEDs were wired in a series circuit ensuring the same drive current and luminosity output. Cooling was

TABLE 1. Specifications, materials, and approximate cost of drop-camera system (excludes all labour costs for design, construction of materials, and assembly of the system).

\begin{tabular}{lll}
\hline \hline Drop-camera & & Estimated cost, \\
components & Materials and specifications & 2010 CAD \\
\hline Housing & Acrylonitrile butadiene styrene tubing & \\
& Clear windows were manufactured out of 1.9-cm-thick polycarbonate & 800 \\
Depth rating of 240 m in seawater & Closed-circuit colour television (Panasonic) & \\
Camera & Auto-focus and auto-aperture & \\
& 350 lines colour resolution & 500 \\
Twin LEDs & 1000 lumens & \\
Other camera & Custom electronics and circuitry & \\
electronics & Two power supplies & \\
Conductor cable & 300 m & \\
Topside equipment & Monitor & \\
& Two computers & 2500 \\
& Embedded controller programmed for video data overlay & 3800 \\
\hline
\end{tabular}

Note: GPS = Global Positioning System, $\mathrm{LED}=$ light-emitting diode, $\mathrm{VCR}=$ video cassette recorder, $\mathrm{CAD}=\mathrm{Canadian}$ dollars. 


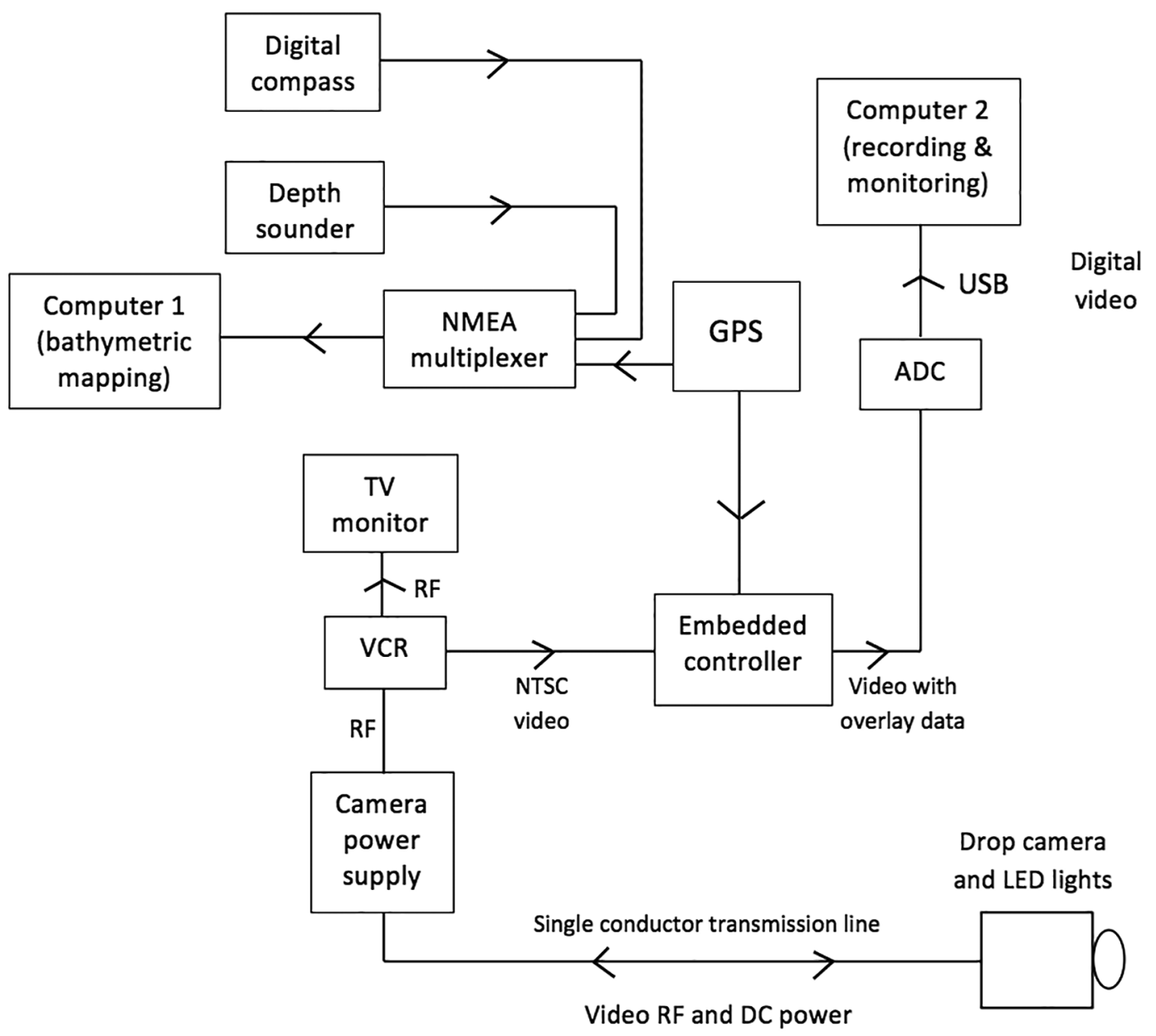

FIGURE 1. Schematic diagram of drop-camera, GPS, and bathymetric charting system. Note: ADC = analog to digital converter, $\mathrm{DC}=$ direct current, GPS $=$ Global Positioning System, $\mathrm{HD}=$ high definition, $\mathrm{LED}=$ light-emitting diode, NMEA $=$ National Marine Electronics Association, NTSC = National Television System Committee, RF = radio frequency, USB $=$ universal serial bus, $\mathrm{VCR}=$ video cassette recorder.

achieved through the walls of the marine housing using two round custom aluminium heat sinks. A closed circuit television (CCTV) camera was powered in the same way as the two LEDs. After separating from the radio frequency signal, the DC power was routed into a linear three-terminal integrated-circuit regulator to reduce and regulate the DC voltage applied to the camera.

\section{Bathymetric Mapping}

Custom bathymetric maps of potential bioherm sites were prepared using DrDepth software (version 5.0.15, created by P. Pelin in 2005, Informer Technologies, Sweden; no longer available) in conjunction with a FishFinder (model 300C, Garmin International, Inc., Olathe, Kansas, USA) with National Marine Electronics Association (NMEA) 0183 output. Positional data from the vessel's electronic compass and the FishFinder were streamed through the NMEA highway to a custom manufactured multiplexer (NMEA 0183 Multiplexer, London, United Kingdom) along with temperature, depth, date, and time data producing a virtually continuous string of ASCII data. The multiplexer optically isolated all input channels, accepted and stored the data string, and then converted the transmission rate from 4800 baud to 115200 baud. Before the data string was transmitted to the computer, the transmission level was changed to universal serial bus (USB). The computer received the data stream, and the DrDepth software plotted geo-positional and depth data. The software produced and recorded a series of parallel and perpendicular tracks and then used its averaging algorithms to interpolate depths between points and produce twodimensional and three-dimensional bathymetric maps resolved to approximately $3 \mathrm{~m}$ on the surveyed seafloor 


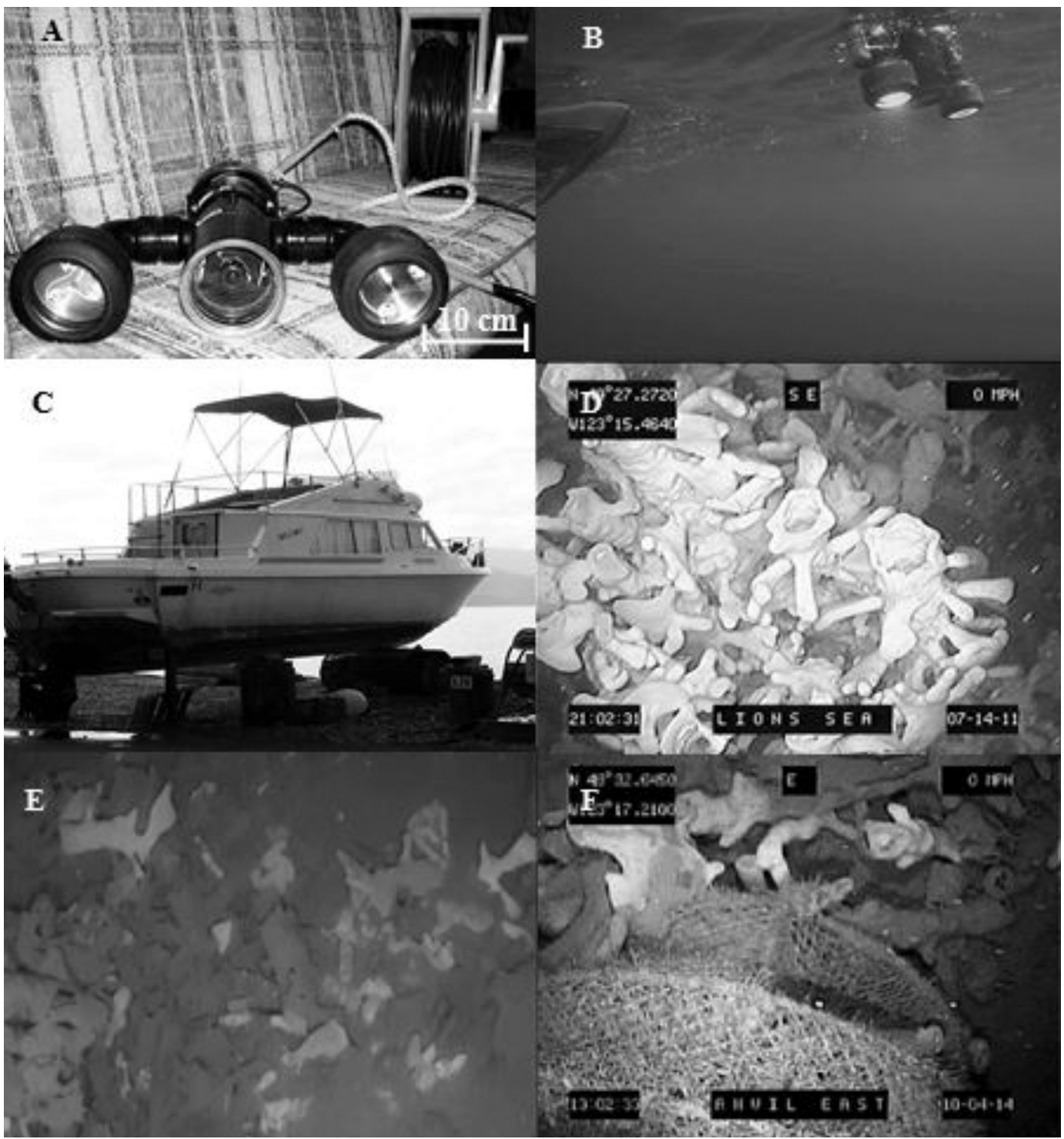

Figure 2. A. Drop-camera with LEDs and cable reel. Photo: G. Dennison. B. Drop-camera suspended over bow of boat. Photo: R. Mulder. C. 7.2-m boat employed for surveys. Photo: G. Dennison. D. Screenshot from drop-camera video footage of glass sponge bioherm. Note: although the GPS data overlay displayed minutes to four decimal places, accuracy was not that precise and the fourth number was always reported as a zero. Photo: G. Dennison and L. Clayton. E. Screenshot from supplemental high-definition video camera showing recent damage to glass sponge in Kelvin Grove Seamount bioherm. Photo: G. Dennison and L. Clayton. F. Screenshot from drop-camera showing crab/prawn trap in Anvil East bioherm. Photo: G. Dennison and L. Clayton.

(Dennison 2012: 19,137). The final output was a database of bathymetric maps saved as DrD files.

\section{Drop-camera Deployment}

Exploratory video transects using the drop-camera were conducted at 20 sites throughout Howe Sound from 2011 to 2015 to investigate potential bioherm sites. The transects were conducted on mapped ridges and seamounts with depths of $20-100 \mathrm{~m}$, in locations with bathymetric features similar to those at confirmed bioherms in the Strait of Georgia (Krautter et al. 2001; Leys et al. 2004; Conway et al. 2005; Cook et al. 2008; Chu and Leys 2010). The drop-camera was lowered over the bow of a 7.6-m boat with a cable on the bow rollers (Figures 2B and C). The umbilical cable was a 305-m spool with radio frequency signal and DC power slip ring to operate the camera while it was being lifted 
and lowered, which allowed the cable to serve as both the mechanical tether and the feed-line for the signal and power. Camera depth was controlled by handlifting and lowering the umbilical cable.

After lowering the drop-camera into the water, the vessel engine was turned off and the camera and vessel were allowed to drift over the study area. A real-time display on topside monitors allowed for depth adjustment as the camera was towed above the substrate to avoid contacting the bottom. The vessel's surface position, derived from a chart plotter (CP160, Standard Horizon, Cypress, California, USA) with a wide-area augmentation system GPS antenna, as well as the time, date, vessel speed, and vessel heading were overlaid on the recorded drop-camera video transects. As the vessel was idle and the drift direction entirely governed by winds and prevailing currents, the drop-camera was not actively towed. Mapping surveys were conducted only when favourable satellite geometry provided a horizontal dilution of precision reading $\leq 1$. Surveys were conducted at times of low wind and current to mitigate some of the positional errors that will occur with dropcameras released at such depths. For the purpose of this study, the camera location was assumed to be within the GPS horizontal positioning error of the vessel.

\section{SCUBA Survey}

SCUBA surveys were initially conducted at five shallower sites to investigate the presence of glass sponge bioherms. Subsequent to initial dive discovery, drop-camera transects were conducted to survey and collect geo-positional data on confirmed bioherm sites (Table 2).

\section{Video Observations}

Multiple transects were conducted in the same area to investigate features of interest, confirm bioherm presence, and delineate the area of sponge coverage. Video data were reviewed to identify glass sponge species (Aphrocallistes vastus or Heterochone calyx), substratum, and the presence or absence of bioherms. A substratum that appeared soft, silty, and complex (evidence of ancestral glass sponge detritus) was considered indicative of bioherm presence as was live glass sponge coverage greater than $50 \%$ in video frames. When both of these conditions were met, the GPS coordinates were designated as a site for a bioherm (Figure 2D).

A centre was assigned to each survey site. Central points for non-pinnacle bioherm sites were calculated by averaging the Cartesian coordinates surveyed that were considered positive for bioherm habitat. Central points for bioherms located on pinnacles were derived

TABLE 2. Locations in Howe Sound, British Columbia, where presence or absence of glass sponge bioherms was confirmed.

\begin{tabular}{|c|c|c|c|c|c|c|}
\hline \multirow{2}{*}{$\begin{array}{l}\text { Study } \\
\text { site* }\end{array}$} & \multirow{2}{*}{$\begin{array}{l}\text { Detection } \\
\text { method }\end{array}$} & \multirow[b]{2}{*}{ Bioherm name } & \multirow{2}{*}{$\begin{array}{l}\text { Date of } \\
\text { discovery }\end{array}$} & \multicolumn{2}{|c|}{ Location (centre) } & \multirow{2}{*}{$\begin{array}{l}\text { Depth at } \\
\text { centre, } \mathrm{m}\end{array}$} \\
\hline & & & & Latitude, $\mathrm{N}$ & Longitude, W & \\
\hline \multicolumn{7}{|c|}{ PRESENCE OF GLASS SPONGE BIOHERM CONFIRMED } \\
\hline 1 & Previously discovered & Defence Island Inshore & N/A & $49^{\circ} 34.660^{\prime}$ & $123^{\circ} 16.410^{\prime}$ & N/A \\
\hline 2 & SCUBA diving & Defence Island Pinnacle & 14 November 2010 & $49^{\circ} 34.690^{\prime}$ & $123^{\circ} 16.266^{\prime}$ & 31 \\
\hline 3 & Drop-camera & Anvil Island East & 4 October 2014 & $49^{\circ} 32.640^{\prime}$ & $123^{\circ} 17.220^{\prime}$ & 88 \\
\hline \multirow[t]{5}{*}{4} & Drop-camera & Christie Islet A & 22 October 2011 & $49^{\circ} 29.663^{\prime}$ & $123^{\circ} 17.831^{\prime}$ & 38 \\
\hline & Drop-camera & Christie Islet B & 22 October 2011 & $49^{\circ} 29.676^{\prime}$ & $123^{\circ} 17.919^{\prime}$ & 43 \\
\hline & Drop-camera & Christie Islet C & 22 October 2011 & $49^{\circ} 29.728^{\prime}$ & $123^{\circ} 17.965^{\prime}$ & 42 \\
\hline & Drop-camera & Christie Islet D & 22 October 2011 & $49^{\circ} 29.730^{\prime}$ & $123^{\circ} 17.879^{\prime}$ & 44 \\
\hline & Drop-camera & Christie Islet E & 22 October 2011 & $49^{\circ} 29.808^{\prime}$ & $123^{\circ} 17.949^{\prime}$ & 45 \\
\hline 5 & SCUBA diving & Lost Reef & 31 January 2010 & $49^{\circ} 29.760^{\prime}$ & $123^{\circ} 17.880^{\prime}$ & 51 \\
\hline 6 & Drop-camera & Brunswick Point & 9 March 2013 & $49^{\circ} 28.408^{\prime}$ & $123^{\circ} 15.003^{\prime}$ & 87 \\
\hline 7 & Drop-camera & Lions Bay Seamount & 8 June 2011 & $49^{\circ} 27.277^{\prime}$ & $123^{\circ} 15.477^{\prime}$ & 72 \\
\hline 8 & Drop-camera & Kelvin Grove Seamount & 14 April 2012 & $49^{\circ} 27.120^{\prime}$ & $123^{\circ} 14.820^{\prime}$ & 77 \\
\hline 9 & SCUBA diving & Halkett Point North & 30 June 1996 & $49^{\circ} 26.760^{\prime}$ & $123^{\circ} 18.720^{\prime}$ & 32 \\
\hline 10 & Drop-camera & South Bowyer A & 22 February 2014 & $49^{\circ} 24.631^{\prime}$ & $123^{\circ} 16.111^{\prime}$ & 79 \\
\hline 11 & Drop-camera & South Bowyer B & 22 March 2014 & $49^{\circ} 24.547^{\prime}$ & $123^{\circ} 16.125^{\prime}$ & 82 \\
\hline 12 & Drop-camera & Cates Bay & 14 February 2015 & $49^{\circ} 24.779^{\prime}$ & $123^{\circ} 18.199^{\prime}$ & 96 \\
\hline 13 & SCUBA diving & Dorman Point & 6 October 2012 & $49^{\circ} 22.440^{\prime}$ & $123^{\circ} 19.260^{\prime}$ & 46 \\
\hline 14 & SCUBA diving & Passage Island South- & & & & \\
\hline \multirow{3}{*}{15} & & West Complex & 27 May 1984 & $49^{\circ} 20.259^{\prime}$ & $123^{\circ} 18.888^{\prime}$ & 24 \\
\hline & Previously discovered & Passage Island SE & & & & \\
\hline & & $\begin{array}{l}\text { Complex (also referred } \\
\text { to as Howe Reef) }\end{array}$ & N/A & $49^{\circ} 20.220^{\prime}$ & $123^{\circ} 17.700^{\prime}$ & N/A \\
\hline \multicolumn{7}{|c|}{ ABSENCE OF GLASS SPONGE BIOHERM CONFIRMED } \\
\hline A & Drop-camera & Porteau Sill & 10 May 2014 & $49^{\circ} 33.600^{\prime}$ & $123^{\circ} 16.500^{\prime}$ & 89 \\
\hline $\mathrm{B}$ & SCUBA diving & Halkett Point South East & July 1996 & $49^{\circ} 26.720^{\prime}$ & $123^{\circ} 18.570^{\prime}$ & 40 \\
\hline $\mathrm{C}$ & Drop-camera & Halkett Point South & 9 May 2015 & $49^{\circ} 25.980^{\prime}$ & $123^{\circ} 19.020^{\prime}$ & 152 \\
\hline $\mathrm{D}$ & Drop-camera & Hutt Island West & 23 May 2015 & $49^{\circ} 24.240^{\prime}$ & $123^{\circ} 24.240^{\prime}$ & 96 \\
\hline
\end{tabular}

*Sites are shown on Figure 3.

Note: N/A = not available. 
from the GPS coordinate of the summit. For sites with no bioherms, we used the average of all coordinates surveyed to calculate the central point. The central geospatial coordinate was calculated using the averaged Cartesian coordinates $(X, Y, Z)$ in a Pythagoras-based formula as follows:

\section{Results}

Latitude $($ radian $)=\arctan 2\left(\left(X^{2}+Y^{2}\right)^{1 / 2}, Z\right)$

Longitude $(\operatorname{radian})=\arctan 2(X, Y)$

Between 2011 and 2015, 12 glass sponge bioherm locations were discovered at depths of 38-96 m in Howe Sound using drop-camera surveys (Table 2).
We identified glass sponge bioherms throughout the northern and southern ranges of Howe Sound, but bioherms were limited to the eastern side of the fjord (Figure 3). Five of the identified bioherms have minimum depths between $24 \mathrm{~m}$ and $51 \mathrm{~m}$. These were the sites first discovered and surveyed by SCUBA diving; the other 12 sites are deeper (centre depths 38-96 m) and were discovered using the drop-camera system.

Four sites (Porteau Sill, Halkett Point South East, Halkett Point South, and Hutt Island West) with favourable bathymetric features for glass sponge bioherms yielded only small or patchy glass sponge gardens or were completely devoid of a glass sponge commu-

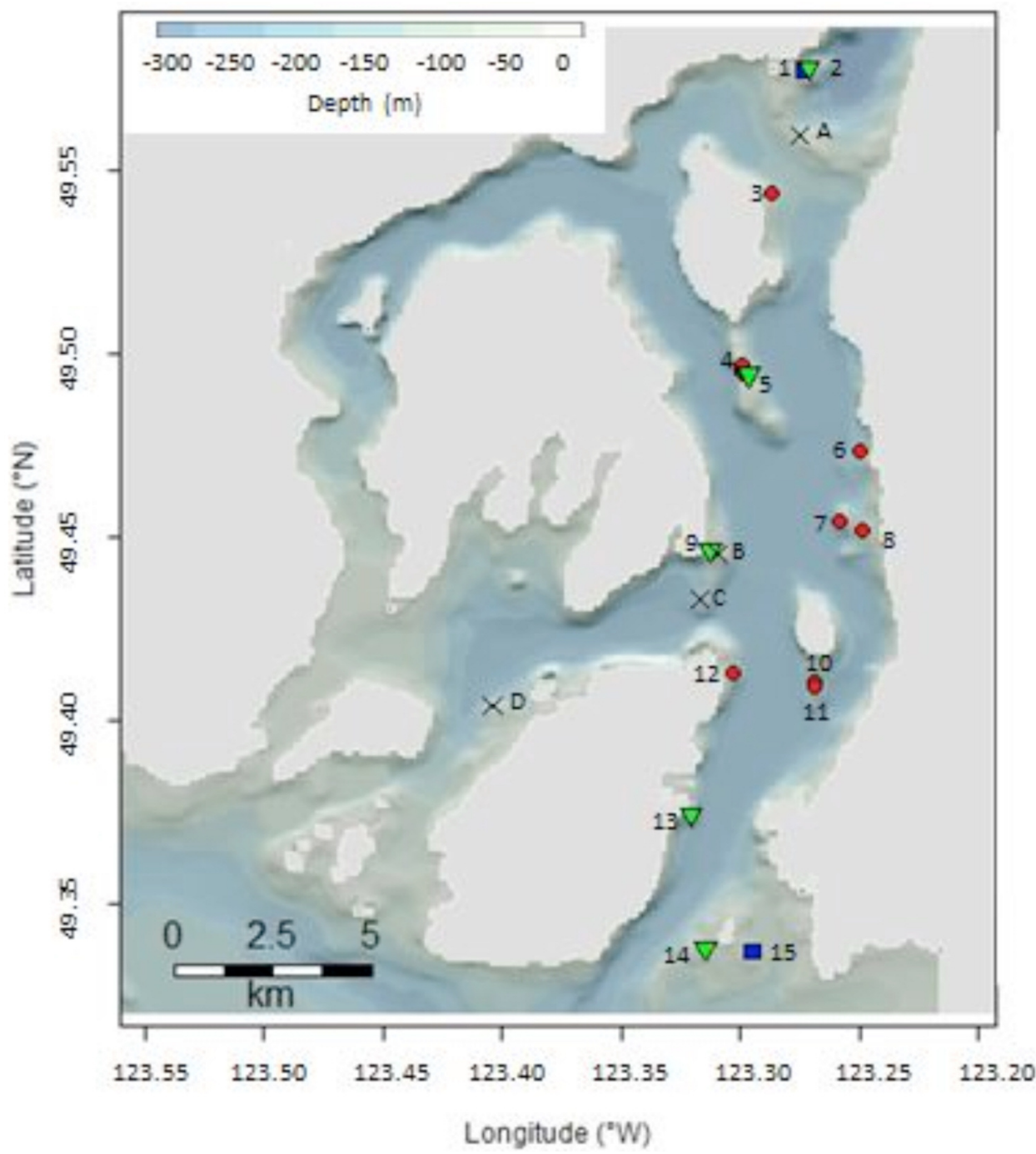

Figure 3. Bathymetric map of Howe Sound, British Columbia, with locations of confirmed presence or absence of glass sponge bioherms discovered through drop-camera method $(\bullet$ and $\times$, respectively) and SCUBA supplemented with drop-camera method $(\boldsymbol{\nabla})$. Previously known glass sponge bioherms $(\boldsymbol{\square})$ are also marked. Numbers and letters identify study sites listed in Table 2 . 
nity (Table 2). Qualitatively, the largest reefs known to date in Howe Sound are those we discovered in the middle of the fjord near Anvil Island and Christie Islet. Both of these are located on underwater ridges rather than pinnacles or seamounts, such as Lost Reef or the Lions Bay Seamount bioherms. Reefs in the middle of the fjord (i.e., Brunswick Point, Kelvin Grove Seamount, and Dorman Point), with the exception of the complex of shallower reefs at Christie Islet, are deeper than those at the far north (i.e., Defence Island Pinnacle) or the far south (i.e., Passage Island South-West Complex).

Three study sites included two or more distinct bioherms within their boundaries. Five distinct bioherms (A to E) were identified in close proximity to each other at Christie Islet. Two separate reefs in close proximity were also identified at Defence Island. South of Bowyer Island, two distinct bioherms were discovered.

Large areas of broken sponges were observed within the bioherms located at Halkett Point North, Kelvin Grove Seamount (Figure 2E), and Anvil Island East. Abandoned prawn traps were observed in the sponge reefs at Anvil Island (Figure 2F) and Kelvin Grove Seamount.

\section{Discussion}

With five bioherms initially discovered by SCUBA between 1984 and 2012, the existing Passage Island SE Complex bioherm (referred to as Howe Reef in some literature) surveyed by Pisces IV in the 1980s (Marliave et al. 2009), and the Inshore Defence Island bioherm discovered by G.D., there are now 19 sites with confirmed glass sponge bioherms in Howe Sound.

The drop-camera proved to be an effective method for locating, as well as ground-truthing, bioherms in sheltered waters such as fjords, coastal regions, estuaries, and inlets where larger equipment may be too cumbersome or function at too coarse a resolution. The drop-camera method is a passive observation tool that allows for great operator control; in the hands of a skilled operator, this method can reduce the risk of contact with glass sponges. However, the use of drifting tows can pose a challenge, because transects follow the direction in which the boat is drifting and are influenced by the prevailing currents and winds, rather than a preferred grid sampling pattern. As well, some positional errors occur when operating at depth in strong currents, as the drop-camera will not lie directly under the vessel, but at an angle.

Most underwater pinnacles and ridges surveyed at depths of $25-100 \mathrm{~m}$ provided positive results for bioherms. These sites were located throughout the middle of the eastern channel of Howe Sound. The most expansive bioherms observed were located in the middle of the sound and were situated on ridges, rather than on pinnacles. The apparently smaller area of other bioherms was likely a result of the physical limitation of space on small pinnacles. Although bathymetric fea- tures proved to be a successful indicator for bioherms at several locations, four sites with promising bathymetry - Halkett Point South East, Halkett Point South, Porteau Sill, and Hutt Island West (Table 2, Figure 3) - did not support glass sponge bioherms.

Although we did not find a bioherm at Halkett Point South, bathymetric features in deep portions of this site $(152 \mathrm{~m})$ resemble those associated with the Halkett Point North bioherm, located $1.49 \mathrm{~km}$ to the north (Figure 3). The Halkett Point South East site, where we also did not find a bioherm, is $200 \mathrm{~m}$ east of the Halkett Point North bioherm and only $8 \mathrm{~m}$ deeper. The absence of glass sponge there might be because of the unsuitability of the site's specific habitat features at greater depth or proximity to the inner channel (i.e., deep currents, sedimentation, sediment load, and silica concentrations). The Porteau Sill site also lacked a glass sponge bioherm, possibly due to insufficient currents. There were no pronounced ridges or pinnacles to direct currents or increase their velocity along this portion of the sill, as is the case at the nearby Defence Island Pinnacle bioherm located on a pinnacle at $31 \mathrm{~m}$ depth and the inshore Defence bioherm on a small ridge. The Hutt Island West site contained clusters of individual glass sponges; however, live sponge coverage was less than $50 \%$ and the substratum was not indicative of a bioherm. We hypothesize that the apparent absence of bioherms here may be a result of contrasts in major current transport of silica divided along the eastern and western sides of the fjord. However, further surveys are required along the western side of the fjord to confirm lack of bioherms in this area.

This drop-camera method has proven successful as a tool for confirming the presence and plotting locations of glass sponge bioherms.

Although it may not be practical for all research groups to undertake the design and construction of a drop-camera system, a variety of drop-cameras capable of operating at $200 \mathrm{~m}$ or more are available off-theshelf at a relatively low cost. Relative to multi-beam sonar, ROVs, and submersibles, our method is both successful and cost-effective at exploring the benthos for glass sponge bioherms. The method is, therefore, accessible to citizen scientists and smaller institutions and organizations.

Beyond surveying the benthos for glass sponge bioherms, this method also provided an unexpected secondary use: as a tool to quantify damage to bioherms from fishing gear. There was evidence of recent damage in all of the bioherms we discovered and surveyed. At some of the sites, there was clear evidence that the damage was caused by contact with fishing lines, anchors, or traps (Figures 2E and F).

These findings identify new bioherm locations in Howe Sound and provide information that can be used to protect these globally unique habitats, in existence since the Devonian (Rigby et al. 2001). 


\section{Acknowledgements}

We sincerely thank Beau Doherty and Jeff Marliave for their invaluable assistance in developing and editing this paper. We appreciate the help of Alejandro Frid in reviewing and editing. We thank Anya Dunham, research scientist at Fisheries and Oceans Canada for sharing her knowledge. We are incredibly grateful to Marine Life Sanctuaries Society, the Vancouver Aquarium, and their all of their team members for their guidance and support.

\section{Literature Cited}

Allwood, R. L. 1986. Environmental monitoring through the use of ROVs. Pages 355-360 in Advances in Underwater Technology, Ocean Science and Offshore Engineering. Volume 5. SpringerNetherlands, Dordrecht, Netherlands. https://doi.org/10.1007/978-94-009-4203-5_41

Beckley, L. E., and G. M. Branch. 1992. A quantitative scuba-diving survey of the sublittoral macrobenthos at subantarctic Marion Island. Polar Biology 11: 553-563. https: //doi.org/10.1007/BF00237948

Chu, J. W. F., and S. P. Leys. 2010. High resolution mapping of community structure in three glass sponge reefs (Porifera, Hexactinellida). Marine Ecology Progress Series 417: 97-113. https://doi.org/10.3354/meps08794

Conway, K. W., J. V. Barrie, W. C. Austin, and J. L. Luternauer. 1991. Holocene sponge bioherms on the western Canadian continental shelf. Continental Shelf Research 11: 771-790. https://doi.org/10.1016/0278-4343(91)90079-L

Conway, K. W., J. V. Barrie, and M. Krautter. 2005. Geomorphology of unique reefs on the western Canadian shelf: sponge reefs mapped by multibeam bathymetry. GeoMarine Letters 25: 205-213. https://doi.org/10.1007/s00367 $-004-0204-z$

Conway, K. W., M. Krautter, J. V. Barrie, and M. Neuweiller. 2001. Hexactinellid sponge reefs on the Canadian continental shelf: a unique "living fossil." Geoscience Canada 28: 71-78.

Cook, S. E., K. W. Conway, and B. Burd. 2008. Status of the glass sponge reefs in the Georgia Basin. Marine Environmental Research 66: S80-S86. https://doi.org/10.1016/j .marenvres.2008.09.002

Copeland, A., E. Edinger, R. Devillers, T. Bell, P. LeBlanc, and J. Wroblewski. 2013. Marine habitat mapping in support of Marine Protected Area management in a subarctic fjord: Gilbert Bay, Labrador, Canada. Journal of Coastal Conservation 17: 225-237. https://doi.org/10.1007/s11852011-0172-1

Cumings, E. R., and R. R. Shrock. 1928. Niagaran coral reefs of Indiana and adjacent states and their stratigraphic relations. Bulletin of the Geological Society of America 39: 579-620. https://doi.org/10.1130/GSAB-39-579

Dennison, G. 2012. Diving Howe Sound Reefs \& Islands. Colorcraft Ltd., Hong Kong, China.

Everson, I., and M. G. White. 1969. Antarctic marine biological research methods involving diving. Underwater Association of Malta Report 4: 91-95.

Fisheries and Oceans Canada. 2016. Strait of Georgia and Howe Sound glass sponge reef fishing closures. Fisheries and Oceans Canada, Ottawa, Ontario, Canada. Accessed 30 September 2016. http://www.pac.dfo-mpo.gc.ca/oceans/pro tection/sponge_reef-recif_eponge-eng.html.
Ghiold, J. 1991. The sponges that spanned Europe. New Scientist 129: 58-62.

Hogg, M. M., O. S. Tendal, K. W. Conway, S. A. Pomponi, R. W. M. Soest, J. Gutt, M. Krautter, and J. M. Roberts. 2010. Deep-sea sponge grounds: reservoirs of biodiversity. Biodiversity series 32. United Nations Environment Programme World Conservation Monitoring Centre, Cambridge, United Kingdom.

Kendall, M. S., O. P. Jensen, C. Alexander, D. Field, G. McFall, R. Bohne, and M. E. Monaco. 2005. Benthic mapping using sonar, video transects, and an innovative approach to accuracy assessment: a characterization of bottom features in the Georgia Bight. Journal of Coastal Research 21: 1154-1165. https://doi.org/10.2112/03-0101R.1

Krautter, M., K. W. Conway, J. V. Barrie, and M. Neuweiller. 2001. Discovery of a "living dinosaur": globally unique modern hexactinellid sponge reefs off British Columbia, Canada. Facies 44: 265-282. https://doi.org/10 $.1007 / \mathrm{BF} 02668178$

Lamb, J. B., J. D. True, S. Piromvaragorn, and B. L. Willis. 2014. Scuba diving damage and intensity of tourist activities increases coral disease prevalence. Biological Conservation 178: 88-96. https://doi.org/10.1016/j.biocon.2014 .06 .027

Leys, S. P., and G. J. Tompkins. 2004. Glass sponges arrest pumping in response to increased sediment loads. Integrative and Comparative Biology 44: 719. https://doi.org/10 .1007/s00227-008-0987-y

Leys, S. P., K. Wilson, C. Holeton, H. M. Reiswig, W. C. Austin, and V. Tunnicliffe. 2004. Patterns of glass sponge (Porifera, Hexactinellida) distribution in coastal waters of British Columbia, Canada. Marine Ecology Progress Series 283: 133-149. https://doi.org/10.7939/R3H41JQ09

Marliave, J. B., K. W. Conway, D. M. Gibbs, A. Lamb, and C. Gibbs. 2009. Biodiversity and rockfish recruitment in sponge gardens and bioherms of southern British Columbia, Canada. Marine Biology 156: 2247-2254. https://doi.org /10.1007/s00227-009-1252-8

McGarvey, R., J. E. Feenstra, S. Mayfield, and E. V. Sautter. 2010. A diver survey method to quantify the clustering of sedentary invertebrates by the scale of spatial autocorrelation. Marine and Freshwater Research 61: 153-162. https://doi.org/10.1071/MF08289

Micallef, A., T. P. Le Bas, V. A. Huvenne, P. Blondel, V. Hühnerbach, and A. Deidun. 2012. A multi-method approach for benthic habitat mapping of shallow coastal areas with high-resolution multibeam data. Continental Shelf Research 39: 14-26. https://doi.org/10.1016/j.csr.2012 .03 .008

Morrison, M., and G. Carbines. 2006. Estimating the abundance and size structure of an estuarine population of the sparid Pagrus auratus, using a towed camera during nocturnal periods of inactivity, and comparisons with conventional sampling techniques. Fisheries Research 82: 150-161. https://doi.org/10.1016/j.fishres.2006.06.024

Neves, B. M., C. Du Preez, and E. Edinger. 2014. Mapping coral and sponge habitats on a shelf-depth environment using multibeam sonar and ROV video observations: Learmonth Bank, northern British Columbia, Canada. Deep Sea Research Part II: Topical Studies in Oceanography 99: 169183. https://doi.org/10.1016/j.dsr2.2013.05.026

Rigby, J. K., A. Pisera, T. T. Wrzolek, and G. Racki. 2001. Upper Devonian sponges from the holy cross mountains, central Poland. Palaeontology 44: 447-488. https://doi.org $/ 10.1111 / 1475-4983.00187$ 
Rooper, C. N., K. Williams, A. De Robertis, and V. Tuttle. 2015. Effect of underwater lighting on observations of density and behavior of rockfish during camera surveys. Fisheries Research 172: 157-167. https://doi.org/10.1016/j.fish res.2015.07.012

Strong, M., and P. Lawton. 2004. URCHIN - manuallydeployed geo-referenced video system for underwater reconnaissance and coastal habitat inventory. Technical report of fisheries and aquatic sciences: Fs97-6/2553E. Fisheries and Oceans Canada, St. Andrews, New Brunswick, Canada.

Tompkins-MacDonald, G. J., and S. P. Leys. 2008. Glass sponges arrest pumping in response to sediment: implications for the physiology of the hexactinellid conduction system. Marine Biology 154: 973-984. https://doi.org /10.1007/s00227-008-0987-y

Vandermeulen, H. 2007. Drop and towed camera systems for ground-truthing high frequency sidescan in shallow waters. Canadian technical report of fisheries and aquatic sciences 2687. Fisheries and Oceans Canada, Dartmouth, Nova Scotia, Canada.

Wassenberg, T. J., G. Dews, and S. D. Cook. 2002. The impact of fish trawls on megabenthos (sponges) on the north-west shelf of Australia. Fisheries Research 58: 141151. https://doi.org/10.1016/S0165-7836(01)00382-4

Yahel, G., F. Whitney, H. M. Reiswig, D. L. EerkesMedrano, and S. P. Leys. 2007. In situ feeding and metabolism of glass sponges (Hexactinellida, Porifera) studied in a deep temperate fjord with a remotely operated submersible. Limnology and Oceanography 52: 428-440. https:// doi.org/10.4319/lo.2007.52.1.0428

Ybarra, R. 2015. Accuracy assessment of depth estimates from variation in pre-and post-processing of multi-beam SONAR surveys in a fjord environment. Undergraduate senior thesis, Washington University, Seattle, Washington, USA.

Received 24 May 2016

Accepted 12 December 2016 